\title{
A Comparative Study of the Social Background, Functions and Types of the Ethnic Minority Property Rights System between the US, Canada and China
}

\author{
Gu Jijian \\ Chongqing Vocational College of Transportation, Chongqing Jiangjin 402247
}

\begin{abstract}
There are obvious differences of the property rights system between the United States, Canada and China's ethnic minorities. They are reflected in differences of social background, the functions of property rights systems, and the types of property rights systems. From the perspective, the development of the property rights system is different from the general conclusions of the Demsetz.
\end{abstract}

\section{Introduction}

Western economists headed by Demsetz have conducted case comparison studies, and then deduced and analyzed them to find the theoretical origin of the establishment of the property right system. Then, the process of studying the property rights system of China's ethnic minorities is similar to Demsetzs', only the differences in social times and social backgrounds. From the prerequisites and basic assumptions of the origin of the national property rights system, the gap is not large, because he did not analyze the social differences between the two. Therefore, when we study the test and response of the Chinese minority property rights system to the origin of the western property rights system, we also start with a case comparison, and also take into account the changes in the property rights system of the American and Canadian Indian tribes at that time and through comparison, analysis, induction, and deduction, and draw the conclusions to be studied in this subject. At the same time, We analyze whether the Chinese minority property rights system, which is in line with the conclusions of the western property rights system origin theory.

\section{A comparison of the social property rights system of Chinese ethnic minorities and the social background of American and Canadian Indian tribes}

From e. Licock, fg Spike, f. Drewlet to Demsetz, their research and inspection time of foreign "minorities"1

[1]I still treat the American Indian tribes as a minority in the United States. Although the Indian tribes are indigenous peoples, because of the power of the invaders, including population, national machinery, ideological propaganda, cultural invasion, etc., the original main ethnic group has been changed. It has become a "minority", which is fundamentally different from the Chinese minority. The former is a property rights system is mainly concentrated in the 1630 s to the 1730 s, such as Licock's research on the records of 1633-1634 and f. Droulett's conclusions on 1647-1648 Then, Demsetz's anonymous record research in 1723 proved the background of their studies. The background of our study of the Chinese minority property rights system was the beginning of the $21 \mathrm{st}$ century, and it is necessary to use the time of the study as a comparative study. Scientific, otherwise it may just be a comparative study of the literature, and it will lose the significance of comparative research.

From 1607-1733, Britain successively established 13 colonies on the Northeast Atlantic coast of North America. The establishment of these 13 colonial strongholds was a process that impacted the original Indian tribe and a process that destroyed the property system of the original Indian tribe. In the battle for the founding of the country, the state of society was very chaotic and what about the construction of Indian private property rights? Even the basic right to subsistence is likely to be lost, personal rights are difficult to protect, and the social environment in which the property rights system can change has been destroyed. How to establish, let alone how to compare such a social background with Indian tribes in Canada. Since such comparative studies are difficult to form a correlation, how can we draw the classic conclusion "the origin of private property rights"? "The Indian tribes of the U.S. were in the era of 'Indian migration,' a process that essentially freed up white people the land between the Appalachians and Mississippi to grow cotton in the South and Grains in the North. The white expand land, develop immigrants, digging canals, build railways and new cities, then establish an enormous empire which across the continents and link the Pacific. We cannot accurately calculate the number of Indians who lose their lives in the process, not to mention the hardships they

derogatory term (referring to the American Indian tribe) and the latter is a neutral term. 
suffered.2In this context, can the Indians establish a private property rights system that meets the needs of the market? Then I dare to criticize Demsetz with Howard Zinn, criticizing it to beautify social reality as a politician and the origin of private property rights3.

At that time, how about the living environment of Indians in northern Quebec of Canada? At the beginning of the $17^{\text {th }}$ century, French explorers Samuel de Champlain established North America's first permanent settlement in Quebec at the same time, fur trades rose in Five Great Lakes district and French Louisiana. To fight for control of the fur trade, Algonquin Tribe fight with Iroquois tribe separately with the support of Britain, the Netherlands and France, which is known as Beaver war, the British-French war in Canada later was for the control of beaver fur trade. This background is naturally different from the environment of American Indian tribes. Canadian colonial masters fought for some kind of profitable property rights system, and it was between the colonial sovereigns, which has created an opportunity for the Canadian Indian tribes to add value to their beaver fur. At this time in Canada, there was neither a "civil war" nor the impact to the original living environment of the Quebec Indian tribes. The property rights can be defined and divided for the value of beaver fur, and they are most oppressed by the suzerain, rather than driven and killed with blood and tears in the United States. Therefore, the Canadian Indian tribes established the private ownership of the Demsetzs' property rights system is understandable, but in turn, it is believed that the American Indian tribe cannot determine that its private property rights system is not "the benefits of internalization are greater than the costs of internalization, and people will adapt to the changes and establish new poperty rights system in order to internalize externalities "(Demsetz), this conclusion is unconvincing, and the conclusion cannot be established that the benefit of the Canadian Indian tribe at this time for the beaver's fur is that the internalization benefit is greater than the internalization cost and the property rights system is internalized from externalities, because at this time all trade issues and property rights issues of Canadian Indian tribes are not purely internalization issues, on the contrary, they are external issues. External incentive opportunities (instead of Mechanism) prompted them to establish a simple property right system based on ethnic habits, how can it be internalized?

The current social background of the evolution of China's ethnic minority property rights system is the promotion of a socialist market economy (where Demsetz's theory of property rights prevails) and the socialist transformation of minorities, which are mainly

[2]Howard Jinn: The History of the American People, translated by $\mathrm{Xu}$ Xianchun and others, Shanghai People's Publishing House, October 2000.

[3]At this time, it is emphasized again that to oppose certain views, theories, and individuals for the sake of opposition, the theory created by anyone may be "half right and half wrong", sometimes right and sometimes wrong, or the adaptability of conclusions as conditions change. It will be greatly discounted. I largely agree with the practicality and practicality of western economics, but I do not agree with its premise. Therefore, my view of the theory is that "any theory is neutral in general" and does not have Completeness and completeness. reflected in the compulsory implementation of market-oriented behavior of the private property rights system and straightly transform the ethnic minorities in various social states to the socialist stage. There are three characteristics: First, the state of social development is very peaceful, without any turbulence and external invasion, and it will not use force to break the ecology of the ethnic minority's original property rights system; second, The nation's implementation of a unified property rights system is actually the process of sinicizing the western property rights system theory, forming a mainstream property rights system model with Chinese characteristics, that is, a public-private mixed property rights system with a shared property rights system that prevails, while allowing minorities to have unique property rights systems. The third is to directly transform a group of ethnic minorities in the primitive society and feudal society to a socialist society, and their original property rights system has also changed, but the direction is uncertain. The social environment of China's ethnic minority property rights system development is quite different from that of American and Canadian Indian tribes, as long as the original property rights system is not broken, the current social peaceful environment will not suddenly break its development trajectory. Therefore, the study of the evolution model of China 's minority property rights system is dominated by natural evolution and the market economy is a factor that induces changes, then gradually and chronically studies and demonstrates the development of China 's ethnic minority property rights system. Through comprehensive research on the relevant literature on the Chinese ethnic minority property rights system and the author 's two research groups on the minority ethnic property rights system, we obtain four modes of property rights systems. They are centralized property sharing, regulatory, chaotic, and mainstream-like. These four models do not have strict boundaries but are based on the system structure, functional categories and stability of their property rights systems. And because of the instability caused by the backflow phenomenon in the property rights system in these four models, the evolution of the property rights system of Chinese ethnic minorities will never be the kind of thinking and basic conclusions under assumptions of western economic theory. For example, the hypothesis that the economic person is selfish and motivated by altruism results in The Mosuo ethnic group in China does not exist at all. The Mosuo people "shared children and made it possible to treat each child as their own, and to take care of the children as a group, not just family behavior." What's more, the privatization of other property rights such as other properties? Taking self-interest as the center is regarded as a shame in some ethnic minority areas such as the Mosuo people. The development exclusive property rights of Demsetz (1967) are probably feasible among the Mosuo people. Therefore, the assumptions and conclusions of Western property rights system theory are difficult to establish in the Mosuo ethnic group in the Naxi branch of China. It is not that the Mosuo people do not have private property rights, but that their private property rights are neither the result of externalization cost and externalization benefit, nor the result of internalization cost and internalization benefit, it is a collectivist distribution and sharing model, which 
is basically characterized by "even rich and poor", or some kind of "on demand" distribution. Some scholars may continue to ask whether such a property right system is efficient? We will discuss this in the third part of Section IV of this chapter.

\section{Comparison of the Evolution of the Property Rights System of Chinese Ethnic Minorities and the Western Mainstream Property Rights System}

In order to make a comparative study of the differences between the Chinese minority property rights system and the western mainstream property rights system, it is necessary to determine the basis for comparative analysis, which is based on the results of experiments and interviews with different groups. This comparison is mainly based on economic efficiency, social harmony and Happiness index (satisfaction with the informal system of ethnic groups). (1) Whether the economic efficiency of China's ethnic minority property rights system is low or high, there is a special measurement in the second part of this chapter ((2) the test and reflection on the impact of regional economic performance), and the conclusions are also in line with our judgments;(2) The second comparative analysis is based on social harmony. Precisely speaking, ethnic minorities whose customary law (informal system) has a deeper impact have a higher degree of social harmony, especially for ethnic minorities who have customary law as their national legal rights. Even if customary law is not regarded as the national legal right, the adjustment of customary law in a large number of ethnic societies and social harmony is still relatively high. Yang Jianchao(2011), Jiang Haiping(2010), Han Hongwei (2009) and other studies on the social function of customary law of ethnic minorities support this view, and its positive effect is very obvious. Unfortunately, he did not quantify it through models; (3) The happiness index refers to the satisfaction of ethnic minorities with the informal system of their ethnic group. Nearly $80 \%$ of Yi property rights disputes are regulated by "Degu" and the results of random inspection of 500 individuals from ethnic minorities show that they are quite satisfied with their informal system and are willing to abide by its constraints. Their psychological satisfaction degree is relatively high. This is an incredible result in the developed West, but it is a fact.

In the social background of the American and Canadian Indian tribes, it is concluded that the process of ignoring other factors and focusing only on how the private property rights system is established is questionable. The social background of the development of the Chinese minority property rights system is quite different from that of the American and Canadian Indian tribes. Does this mean that there is no comparable scope between them? In fact, that is not the case. The mainstream property rights system of the socialist market economy promoted by China is actually the sinicization of western property rights system theories, naturally in some field they have a comparable framework, which is mainly reflected in structure, function, type, efficiency (4.3) and trend (4.4), etc.
Among them, the comparison of efficiency between them is discussed in part III of section IV of this chapter, and the comparison of property rights system trends is discussed in part IV of section IV of this chapter.

\section{The first is the structure comparison of the property rights system between Chinese ethnic minorities and the mainstream property rights system in the West.}

(1)In terms of the microstructure of the property rights system: it mainly examines the property rights structure of the single property or single subject of the minority property rights system. The microstructure is the same in the ownership, domination, use, and income rights of the Chinese minority property rights system and the property rights system of the American and Canadian Indian tribes and any other nation. It is composed of the "four rights", or we can say the core part of the research on the property rights system is the quantitative proportion relationship of these four types of rights bundles. However, the difference is that it affects the ownership, domination, use and the weighting relationship of many factors. In Chapter 4, we measure the informal system (0.52952), natural resources $(0.20642)$, altitude $(0.33036)$, mountain area $(0.3426)$, education factors (0.40926), and transportation facilities (0.40926). 0.42588 ) and other weights that affect the minority property rights system, the results show that different factors have different degrees of influence on the minority property rights system. And we specifically analyze that the reasons for these differences are caused by endogenous and exogenous. The core factor is that the informal system has the greatest impact on the structure of the national property rights system, that is, the informal system affects the property right system's definition of possession, domination, use and income, especially for ethnic minorities with relatively strong collectivist habits. This is a social ecology that Indian tribes in the southwestern United States do not possess, at the same time, they are also obviously different from the individualistic habit of Indian tribes of Quebec, Canada. The result of this substantial difference is naturally a fundamental difference in the property rights system, that is, at least there is a different model or type of property right system in China's ethnic minorities that is completely different from the mainstream property rights system in the West. Whether in terms of origin, evolution, expression, or current mode of operation, it has shown China's unique model of ethnic minority property rights. As for other types, do they conflict with western mainstream property rights or challenge them, we will continue to analyze.(2)In terms of the macro structure of the property rights system: it mainly refers to the main parts and components of various property rights systems in the entire society (for the division of macro and micro structures, refer to Huang Shaoan's "Economics of Economics", page 183). This is mainly reflected in the property structure, the subject of property rights, and " "Four rights entrust-agent" three aspects. First, the property structure refers to how the total amount and proportion of public property are distributed 
among the group. In the Western economic theory system, as long as you see the word "public", it immediately reflects the problem of "tragedy of the commons". In other words, the theory of property rights in western economics requires that the higher the degree of privatization, the better. However, the property rights system of Chinese minorities poses a challenge to it. In theory, the theory should be backward if it does not conform to the Western property rights system, but the development of China in recent decades has really embarrassed the theory of the western property rights system, not to mention how serious the challenges the property rights structure of the Chinese minority property rights system to it. Especially some minorities, the total amount of minority property accounts for most of the minority property, and the main principle is balanced distribution. However, the level of economic development of some ethnic minorities is not low and can accept any vertical and horizontal comparison. Second, the subject of property rights refers to the question of who the property rights belong to. In fact, there is no need to answer. In the Chinese minority property rights system, the subject of property rights is the minority itself, and there is no individual at all. When individuals attempt to infringe ethnic property rights, they will be cast aside by the society and severely punished by national customary laws. This is difficult for Demsetzs to accept. Third, in the four items of "occupation, domination, use and gain" of western property rights, once the occupation right is determined, the other property rights are in a subordinate position. It can be said the other three rights are derived from it, and they are insignificant. The occupation has the power to dominate, use and gain benefit, or transfer to others for use and gain. That is, the freedom and authority of the entrust-agent are determined by the possessor. However, in the "four rights" of the Chinese minority property rights system, most possessors are never individuals, but ethnic groups, and dominate right is controlled by the most prestigious head of the ethnic group and the ethnic committee. The right to use is according to the needs of the ethnic group and the final profit right is owned by the ethnic group, expect for some daily necessities of the family. Even the current Jino individual hunting income is still based on the principle of anyone who see it. This property right system model is very clear in the "four rights" entrust-agent. However, the result still does not appear that who has a large number of income rights with agency rights, while avoiding a lot of polarization.

\section{The second is the function comparison of the property rights system of Chinese ethnic minorities and the mainstream property rights of the West.}

From the perspective of Western scholars, the function of the property right system is reducing the uncertainty, lowering transaction costs, and optimizing the allocation of resources to achieve the purpose of improving economic efficiency. In fact, any property right system has these functions. The difference between them is in two aspects:(1)Each has its own advantages in reducing uncertainty. The private property rights system clarifies the subject of property rights, how to do it, how to use it, and how to benefit from it. It cannot be violated, otherwise it will be punished by laws and pay a lot of money. This cost is the tripartite cost that both parties and the society bear together, especially large-scale civil lawsuits, which may not lower transaction costs. Secondly, compared with the property rights system regulated by the informal system of ethnic groups, this property rights system is based on Collective wisdom to reduce the occurrence of uncertainty, they will still consider transaction costs, the cost control of infringement is much more save than the private property rights system, and the follow-up litigation costs will also be saved, to a certain extent, which actually increase ethnic income, reduce uncertainty, lower transaction costs, optimize resource allocation, and improve economic benefits. "This kind of good-natured method of defining property rights reduces the cost of defining exclusive rights for transactions. If this definition of the cost reduction and the benefits of insurance outweigh the associated costs (assuming no other lower cost insurance exists), then this particular property structure achieves great wealth. "(2)Other social functions, such as security function and regulatory function. This is rare in Western property rights theories and is at best an altruistic result discussion under egoistic motivation. This statement is far-fetched, not as obvious and clear as the Chinese minority property rights system. The public property rights can guarantee everyone's basic living right. It fundamentally changed the so-called "people should take their own independent economic interests as the core, driven by economic interests to pursue the maximized self-interest, ......in the context of economic people's pursuit of maximizing their own interests, but unexpectedly and more effectively promote the interests of society. "It seems that Mr. Smith should accurately define "human nature is good", otherwise things that hurt others will happen all the time, even if not everyone, as long as the probability exceeds $20 \%$ that people choose a model that harms others (we once did a tracking model with 2-8 Principle.). Smith's so-called people's intentions are "good" and objective terms are "good" conclusion is simply false. In Western society, the property rights system is only clear for the division of responsibilities of groups, rather than the protection function. It regulates the social order among people, not the wealth contribution, interpersonal relationships, and distribution relationships among people. However, the Chinese minority property rights system has these functions, and can guarantee the equal realization of Chinese rights for each individual of the ethnic group (generally as long as the patriarch and ethnic committee do not deliberately distort the ethnic group's property rights system). That's the difference in nature. 


\section{The third is the type comparison of the property rights system of Chinese minorities and the mainstream property rights of the West.}

According to the viewpoint of western property rights theory, the property rights system is to ensure the implementation and enforcement of private property rights, and its implementation must be based on marketization, especially the marketization path of the free economy, which is a relatively single implementation path that takes all the elements of property rights in the market and accepts the supply and demand constraints of the market, but not the multi-dimensional path of the Chinese minority property rights system. It can not only conduct market exchange based on internal optimization decisions, but also can completely place in the market and is determined by supply and demand. The practice process of the western property right system theory is not all successful cases. The drastic changes in Central and Eastern Europe and the severe pain of Russia are a failure of this property right system. The types of property rights systems of ethnic minorities in China can be summarized into at least three types. (the four types summarized previously is used to refine the classification, and can be divided into three types): one is the centralized type (centralization and balanced sharing system); the second is the intermediate state, that is, the unclear and mixed property rights system; the third is the Inner Mongolia-type property rights system which is close to the mainstream property rights of the market. The first is a new institutional model that can question current western property rights theories. The second is because of the complexity of ethnic minorities, which has both the elements of the collectivist property rights system, more or less, and the performance of each minority is different. It may be closer to the model of the collectivist property rights system. This possibility is very likely to be made possible by the minorities around the Mosuo, or move towards the mainstream property rights system model, mainly depending on the historical synergy of the development of these ethnic minorities; the third is the type of minority property rights system that is more successful in docking with the mainstream property rights system. In this type, the impact of the informal system on the property rights system and its regulating role have basically been lost, and economic activities have been basically regulated in accordance with the mainstream property rights system.

\section{In short}

We conclude that the rationality of the existence of China's ethnic minority property rights system is enough, and the choice of the minority property rights system should be fully respected. Although it is neither the best property system for human beings nor the worst for human beings. This property right system has both advantages and disadvantages. Among them, the Mosuo property right system is a living fossil in the history of the development of the human property right system. It has advantages and characteristics that the current world property rights systems do not have, and it is also a highly respected model of the property right system. As for other minority property rights systems, I believe that on the basis of respecting their national habits, they are guided to adapt to the socialist market in an induced change manner, and they must strive to retain the national characteristics in their property rights systems, as long as they are not contrary to social development.

\section{About the Author:}

Gu Jijian (1980.8-) male, Han, Shandong Chengwu, professor, doctoral and master tutor of Chongqing Vocational College of Communications, mainly engaged in theoretical research on property rights economy and macroeconomics

Phone: gumuran2006@126.com

Mailing address: No. 555 Xiangfu Avenue, Shuangfu Street, Jiangjin District, Chongqing

Zip code: 402247

\section{Acknowledgement}

This project is a phased achievement of the National Social Science Fund's "Static Comparison and Dynamic Changes of Seven Ethnic Minorities' Property Rights Systems under the 'The Belt and Road Initiative' Strategic System" (2015XJL001); The Fifth Batch of Excellent Talents Funding Program of Chongqing "Research on the Fusion Path of the Intersection of" Three Strategies "-Based on the Perspective of Strategic Behavior of Chongqing Inland Free Port.

\section{References}

1. Ninette Kelley, Michael J. Trebilcock, The Making of the Mosaic: A History of Canadian Immigration Policy, University of Toronto Press. September 30, 2010. 27.

2. Tucker Spencer .C, Arnold James, Wiener Roberta, The Encyclopedia of North American Indian Wars, 1607-1890: A Political, Social, and Military History. ABC-CLIO.

3. Cao Heping, "A Probe into the Common Factor Management of Economic Dynamics Mechanisms among Different Civilizations: A Comparative Study of Sustainable Economic Development Paths between Easter Island and Mosuo People", "Beijing Forum (2011) Harmony and Common Prosperity of Civilizations- Tradition and Modernity, Change and Transformation: "Economic Growth in the Context of Globalization: Opportunities, Challenges and Directions" Papers and Abstracts of the Economic Forum, 2011-11-04, p. 321

4. Siran Eegertson, "New Institutional Economics", translated by $\mathrm{Wu}$ Jingbang and others, Commercial Press, published in 1996, p. 126 
5. Adam Smith, An Inquiry into the Nature and Causes of the Wealth of Nations, London: Methuen and Co.,
Ltd., ed. Edwin Cannan, 1776.p.14 